\title{
Edukasi Hipertensi dan Pelatihan Pembuatan Teh Herbal Kombinasi Daun Pegagan (Centella asiatica) Dan Rimpang Kunyit (Curcuma longa) Sebagai Minuman Kesehatan Antihipertensi
}

\author{
Patonah Hasimun'), Dadang Juanda ${ }^{2}$, Ika Kurnia Sukmawati ${ }^{3)}$, \\ Ari Yuniarto ${ }^{4)}$ \\ Universitas Bhakti Kencana ${ }^{1)}$ \\ Universitas Bhakti Kencana ${ }^{2}$ \\ Universitas Bhakti Kencana ${ }^{3)}$ \\ Universitas Bhakti Kencana ${ }^{4}$ \\ patonah@bku.ac.id
}

\begin{abstract}
ABSTRAK
Kecenderungan jumlah penderita hipertensi yang terus meningkat setiap tahunnya, memerlukan upaya pengendalian untuk mencegah resiko komplikasi kardiovaskular. Secara empiris daun pegagan dan rimpang kunyit telah dimanfaatkan oleh masyarakat untuk mengatasi berbagai macam penyakit termasuk hipertensi. Pemerintah melalui kemenkes telah menetapkan fokus riset dan pemanfaatan bahan alam untuk mengelola hipertensi. Penelitian ini bertujuan untuk memberikan edukasi pengelolaan hipertensi serta pelatihan pembuatan teh herbal yang mengandung daun pegagan dan rimpang kunyit sebagai minuman kesehatan antihipertensi. Kegiatan dilaksanakan di keluraha Padasuka RW05 yang bekerja sama dengan ketua RW dan ketua PKK kelurahan Padasuka. Edukasi dilakukan melalui metode ceramah dan diskusi. Selanjutnya masyarakat mendapat pelatihan cara membuat teh herbal hasil riset kampus yang mengandung daun pegagan dan rimpang kunyit serta pemanis stevia. Kegiatan diakhiri dengan minum teh herbal bersama. Kegiatan ini bermanfaat meningkatkan nilai guna tanaman herbal daun pegagan dan rimpang kunyit yang sudah dikenal oleh masyarakat, meningkatkan pengetahuan untuk mengendalikan hipertensi serta meningkatkan keterampilan masyarakat dalam membuat teh herbal.
\end{abstract}

Kata kunci: Edukasi, Hipertensi, Kunyit, Pegagan

\begin{abstract}
The tendency of increasing numbers of people with hypertension every year requires control efforts to prevent the risk of cardiovascular complications. Traditionally, Centella asiatica and Curcuma longa have been used by the community to overcome various diseases including hypertension. The government through the Ministry of Health has set the focus of research and use of natural medicines to manage hypertension. This research aims to provide education on managing hypertension and training in making herbal teas containing Centella asiatica and Crucuma longa as health drinks to prevent hypertension. Education and training were carried out in Padasuka Urban Village in collaboration with the RW chairman and PKK Chairperson of Padasuka Urban Village. Education is done through lecture and discussion methods. Furthermore, the community received training on how to make herbal tea from the research of the Faculty of Pharmacy, Bhakti Kencana University, which contained Centella asiatica and Curcuma longa and stevia leaves. The activity ended with drinking herbal tea together. This activity is useful to increase the value of the herbs of Centella asiatica and Curcuma longa which are well known by the community, increase knowledge to control hypertension and community skills in making herbal teas.
\end{abstract}

Keywords: Centella asiatica, Curcuma longa, Education, Hypertension 


\section{PENDAHULUAN}

Kecenderungan pola hidup yang tidak sehat akan meningkatkan resiko munculnya penyakit-penyakit kronis yang menjadi beban bagi masyarakat dan pemerintah karena produktifitas individu yang makin menurun. Salah satu penyakit kronis yang dimaksud adalah penyakit hipertensi. Hingga saat ini, prevalensi penderita hipertensi terus meningkat dengan bertambahnya usia (Kementerian Kesehatan Republik Indonesia, 2013). Namun, penyakit kronis, sebenarnya bisa dicegah dengan menjaga pola hidup yang sehat sejak awal.

Masyarakat Indonesia memiliki berbagai warisan alam termasuk obat herbal yang terbukti secara empiris untuk menjaga kesehatan. Diantara bahan alam yang berkhasiat adalah daun pegagan (Centella asiatica) dan rimpang kunyit (Curcuma longa) untuk mengatasi tekanan darah tinggi (BPOM, 2010).

$\begin{array}{clr}\text { Daun } & \text { pegagan } & \text { (Centella } \\ \text { asiatica }) & \text { telah } & \text { dilaporkan }\end{array}$ mengandung senyawa aktif yang berkhasiat untuk kesehatan seperti terpenoid, flavonoid (quersetin dan kaempferol), triterpenoid (asiatikosida, asam asiatik, madekasida, dan madekasosida), glikosida (Bhattacharya, Parmar dkk., 2017; Nansy dkk., 2015).

Kunyit memiliki kandungan yang bermanfaat bagi tubuh seperti zat kuning kurkumin, minyak atsiri, mineral tinggi seperti kalium, kalsium, zat besi dan magnesium. Kalium merupakan suatu komponen penting dari sel dan cairan tubuh yang membantu untuk mengontrol detak jantung dan tekanan darah. Kurkumin yang dimiliki oleh kunyit merupakan zat antioksidan. Kunyit berkhasiat untuk meningkatkan nafsu makan, memperbaiki fungsi pencernaan, menurunkan lemak darah (kolesterol) dan membantu menghambat penggumpal darah (Muti, 2017). Selain itu, menurut hasil uji klinik dengan menggunakan kunyit yang dikombinasikan dengan bulbus bawang putih mampu memperbaiki profil lipid dan mengelola tekanan darah pada pasien diabetes yang disertai hiperlipidemia (Sukandar dkk., 2010). Jus kombinasi daun pegagan dan rimpang kunyit telah terbukti secara praklinik dapat memperbaiki elastisitas pembuluh darah, serta dapat mengelola tekanan darah pada model hewan hipertensi yang diinduksi makanan tinggi lemak dan karbohidrat (Hasimun dkk., 2019).

Kegiatan pengabdian masyarakat yang dilakukan ini merupakan bentuk kontribusi dari hasil penelitian dengan memanfaatkan daun pegagan dan rimpang kunyit menjadi sebuah minuman kesehatan untuk mencegah (atau mengobati) hipertensi dan memperbaiki elastisitas pembuluh darah.

Kegiatan pengabdian kepada masyarakat ini bertujuan untuk memberikan penyuluhan tentang penyakit hipertensi dan terapinya dengan memanfaatkan bahan alam yang ada di sekitar rumah. Kegiatan yang dilakukan meliputi pelatihan pembuatan minuman kesehatan jus dan penggunaan teabag yang berisi kombinasi daun pegagan dan rimpang kunyit. 


\section{METODE PELAKSANAAN}

Kegiatan pengabdian pada masyarakat ini dilakukan melalui beberapa tahapan. Kegiatan diawali dengan pengajuan perizinan pelaksanaan kegiatan di RW 05 kelurahan Padasuka, Cimenyan. Persetujuan dan dukungan dari ketua RW dan ketua PKK kelurahan sangat penting untuk memfasilitasi kegiatan ini. Adanya penyuluhan dan pelatihan yang berkaitan dengan peningkatan kemampuan kader PKK dan masyarakatnya dapat membantu meringankan salah satu tugas dan tanggung jawab pokja PKK di kelurahan Cimenyan.

Tahap kedua, penyuluhan hipertensi dan terapinya dengan memanfaatkan bahan alam yang telah diteliti di kampus Fakultas Farmasi Universitas Bhakti Kencana. Penyuluhan dilaksanakan dengan metode ceramah dan diskusi interaktif untuk meningkatkan pengetahuan dan pemahaman masyarakat terhadap pengelollan hipertensi.

Tahap ketiga, kegiatan pelatihan pembuatan minuman kesehatan dalam bentuk jus dan teh celup (teabag) yang berisi kombinasi daun pegagan dan rimpang kunyit.

\section{Prosedur pembuatan jus}

Daun pegagan sebanyak 700 gram dicuci hingga bersih kemudian dihaluskan menggunakan blender Miyako dengan penambahan aquadest sebanyak $50 \mathrm{ml}$ lalu diperas, air perasan berupa jus pegagan. Sedangkan 700 gram rimpang kunyit dicuci hingga bersih lalu diblender dengan penambahan $20 \mathrm{ml}$ aquadest kemudian diperas, air perasan berupa jus kunyit. Air perasan digabungkan dan ditambahkan pemanis gula stevia (rebusan daun stevia 5\%) hingga volume $100 \mathrm{~mL}$. Jus kombinasi dikemas dalam botol volume $100 \mathrm{~mL}$ dan ditutup kedap. Sediaan jadi sebaiknya disimpan dalam lemari es dan dikonsumsi dalam jangka waktu 3 hari.

\section{Prosedur pembuatan teh celup}

Daun pegagan dan rimpang kunyit dibersihkan dari kotoran dengan air mengalir, kemudian dirajang tipistipis dan kecil-kecil. Hasil rajangan dijemur/dikeringkan pada suhu oven $50^{\circ} \mathrm{C}$ hingga kering. Hasil rajangan yang sudah kering diblender halus dan diayak kemudian dikemas dalam kantong teh sejumlah 350 gram daun pegagan dan 350 gram rimpang kunyit.

Cara pakai:

- Seduh teh dalam $250 \mathrm{~mL}$ air mendidih dan biarkan selama 2-3 menit. Kemudian tambahkan gula rendah kalori (gula stevia) dan jeruk lemon untuk menambah rasa nikmat teh berkhasiat.

- Konsumsi teh sehari 1-2 kali 1 teabag selama 2 minggu berturut-turut.

- Lakukan pemeriksaan tekanan darah untuk memantau tekanan darah secara rutin.

\section{HASIL PEMBAHASAN} DAN

Kegiatan Pengabdian Masyarakat dengan topik "Edukasi Pengendalian Hipertensi Dan Pelatihan Pembuatan Teh Herbal Untuk Kesehatan Pembuluh Darah" di kelurahan Padasuka Cimenyan, Kabupaten Bandung telah dilaksanakan pada tanggal 16 Agustus 2019. 
Kegiatan dihadiri masyarakat dengan menyimak paparan materi edukasi, kemudian dilanjutkan dengan diskusi yang membahas penyebab hipertensi dan pengelolaannya menggunakan bahan alam yang telah diketahui khasiatnya. Diskusi juga membahas bagaimana memperoleh dan mengidentifikasi daun pegagan dan rimpang kunyit yang dapat digunakan. Teknik pengeringan dan cara pembuatan jus dan teh celup dipraktekkan secara langsung sehingga masyarakat memiliki pengalaman praktis untuk membuatnya sendiri. Hasil pembuatan jus dan teh celup kombinasi daun pegagan dan rimpang kunyit diujicoba oleh peserta pelatihan untuk membuktikan bahwa pemanfaatan bahan alam mudah dilakukan dan memiliki rasa yang dapat diterima oleh masyarakat (acceptable) baik dalam bentuk jus maupun teh celup yang praktis.

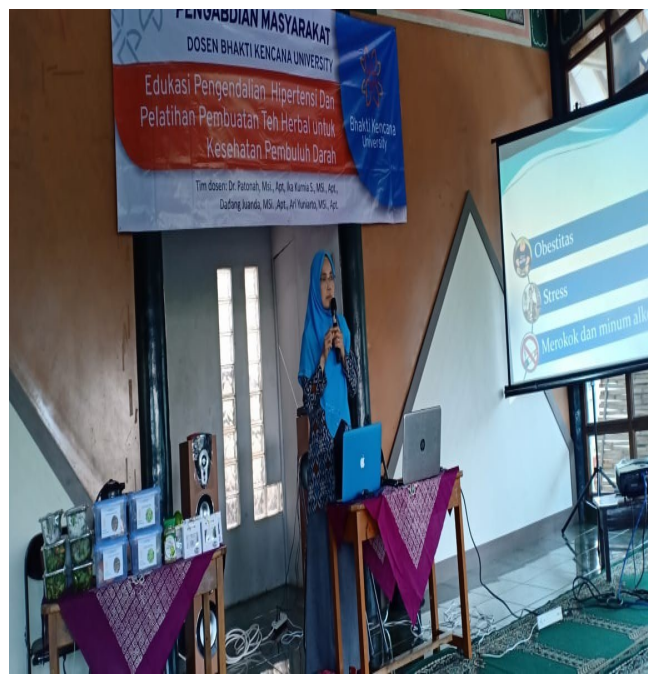

Gambar 1. Tim Penyuluhan FF-UBK Memberikan Edukasi Pengendalian Hipertensi

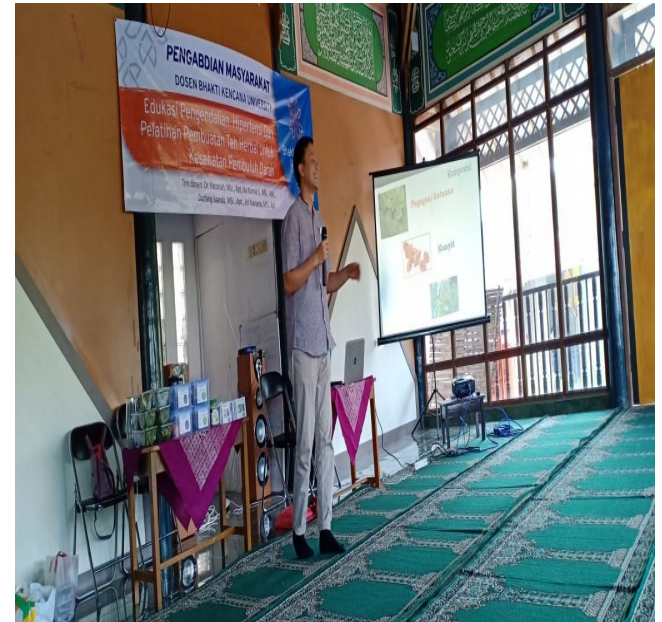

Gambar 2. Tim Penyuluhan Memberikan Penjelasan Tentang Bahan Alam yang Digunakan dan Cara Pembuatan Teh Herbal Yang Mengandung Daun Pegagan dan Rimpang Kunyit.

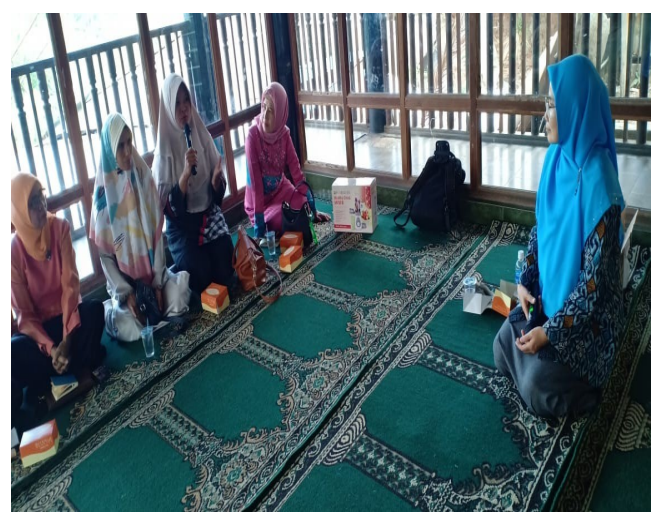

Gambar 3. Sesi diskusi dan tanya jawab seputar kesehatan dan penggunaan bahan alam dalam teh herbal.

Pada saat paparan materi edukasi sebagian besar peserta sangat antusias dalam diskusi yang menggambarkan sudah terbangunnya pemahaman dan kepedulian masyarakat akan bahaya penyakit hipertensi jika tidak dikendalikan dan dicegah sejak awal. Program pengabdian kepada masyarakat yang dilaksanakan oleh dosen-dosen Fakultas Farmasi Universitas Bhakti Kencana diharapkan dapat memberikan kontribusi nyata dalam bentuk aplikasi hasil risetnya yang bermanfaat meningkatkan kesehatan masyarakat serta keterampilan 
masyarakat dalam memanfaatkan bahan alam untuk menjaga kesehatan pembuluh darah. Kegiatan ini diharapkan dapat memberikan kontribusi upaya pengendalian dan pencegahan penyakit hipertensi di masyarakat khususnya Kelurahan Padasuka, Kecamatan Cimenyan, Kabupaten Bandung.

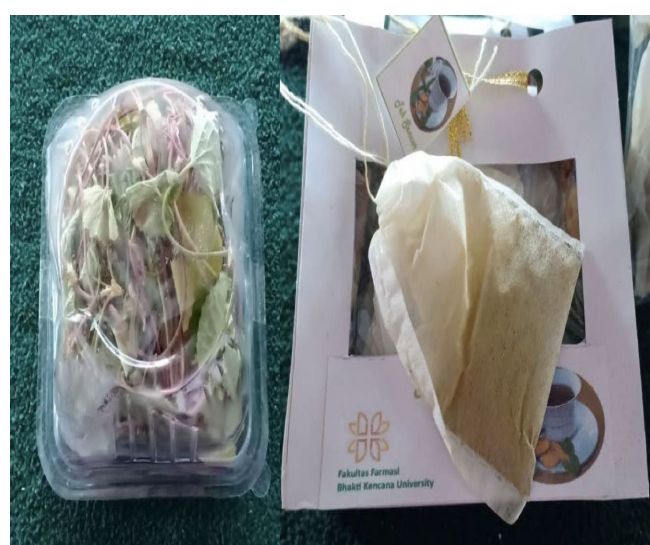

Gambar 4. Produk Teh celup Herbal "Sencur"

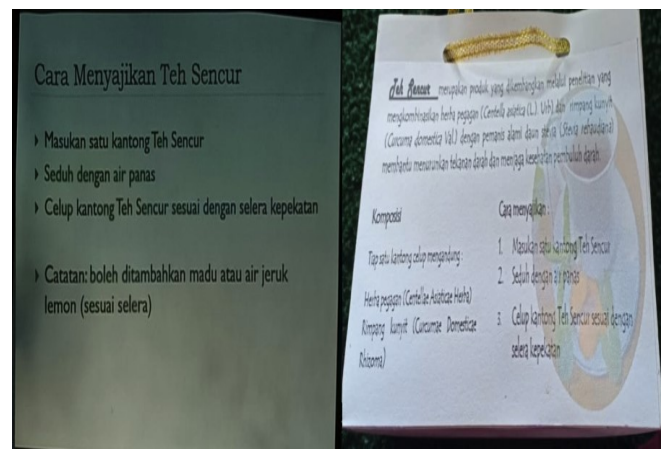

Gambar 5. Kemasan Teh Celup "Sencur" dan Cara Penyajiannya.

\section{KESIMPULAN}

Kegiatan Pengabdian Kepada Masyarakat dengan topik "Edukasi Pengendalian Hipertensi Dan Pelatihan Pembuatan Teh Herbal Untuk Kesehatan Pembuluh Darah" telah terlaksana dengan baik pada tanggal 16 Agustus 2019 di Kelurahan Padasuka, Kecamatan Cimenyan, Kabupaten Bandung. Upaya edukasi hipertensi serta pengendaliannya perlu terus ditingkatkan sebagai bagian dari kewajiban Tridharma dosen Perguruan Tinggi.

\section{UCAPAN TERIMAKASIH}

Peneliti mengucapkan terimakasih kepada Lembaga Penelitian dan Pengabdian Pada Masyarakat Universitas Bhakti Kencana yang telah memberikan dukungan dana dalam kegiatan ini.

\section{REFERENSI}

Bhattacharya, R. D., Parmar, K. M., Itankar, P. R., \& Prasad, S. K. (2017). Phytochemical and pharmacological evaluation of organic and non-organic cultivated nutritional Centella asiatica collected after different time intervals of harvesting. South African Journal of Botany, 112, 237-245.

BPOM, R. I. (2010). Serial Data Ilmiah Terkini Tumbuhan Obat; Pegagan (Centella asiatica (L.) Urban). Jakarta: Direktorat Obat Asli Indonesia.

Hasimun, P., Mulyani, Y., Sulaeman, A., \& Saraswati, D. A. E. (2019). Prevention of Hypertension and Arterial Stiffness by Combination of Centella asiatica and Curcuma longa in Rats. Asian Journal of Biological Sciences, 12(2), 173179.

https://doi.org/10.3923/ajbs.2019 .173 .179

Kementerian Kesehatan RI. (2013). RISKESDAS 2013. Jakarta: Kementerian Kesehatan RI.

Muti, R. T. (2017). Pengaruh Parutan Kunyit Pada Penurunan Hipertensi Pada Lansia Di Kelurahan Berkoh Kecamatan 
Purwokerto Selatan Kabupaten Banyumas. Medisains, 15(2), 84-90.

Nansy, E., Pramono, S., \& Nugroho, A. E. (2015). Total flavonoid content and in vivo hypotensive effect of chloroform insoluble fraction of Centella asiatica leaf extract. International Food Research Journal, 22(5), 2119.
Sukandar, E. Y., Permana, H., Adnyana, I. K., Sigit, J. I., Ilyas, R. A., Hasimun, P., \& Mardiyah, D. (2010). Clinical study of turmeric (Curcuma longa L.) and garlic (Allium sativum L.) extracts as antihyperglycemic and antihyperlipidemic agent in type-2 diabetes-dyslipidemia patients. Int $J$ Pharmacol, 6(4), 456-463. 